\title{
Global research landscape of high-level studies in geosciences based on highly cited papers
}

\author{
Yanlin Cui*
}

The objective of this study was to analyse the characteristics of highly cited papers (HCPs) in the research field of geosciences based on the Essential Science Indicators database, which is widely used to evaluate institutions and researchers. Multi-aspects, including country/region's productivity distribution, organizations, authors, detailed categories and hot topics, journals and implications of collaboration networks have been explored in this study. The main findings are: (1) USA ranks first in geosciences research with over $60 \%$ global share, with most of the leading organizations (12 out of 15) also from that country. (2) The percentage of international collaborations is high in this research field; the collaboration shows tangled networks among countries/regions (organizations) and also indicates close connections worldwide. (3) Despite the dominance of USA in productivity, only 5 of the top 15 authors are from that country, and relatively tight collaboration networks are found among the top authors. (4) The current high-level researches in geosciences focus on meteorology, geochemistry, geophysics, remote sensing and oceanography, and topics involving climate change draw most of the attention.

Keywords: Geosciences, global research, highly cited papers.

GEOSCIENCES, also known as earth science, is the scientific study of the planet Earth, including all fields of natural science related to oceans, atmosphere, rivers and lakes, ice sheets and glaciers, soils, mountains and rocks ${ }^{1}$. This vital science comprehensively integrates the best and latest from physics, chemistry, biology, mathematics and high-performance computation with the ultimate goal of helping us better understand the Earth by studying the past, measuring the present, and modelling the future behaviour of our planet. In this era of global climate change, geosciences play an important part in assisting us learn to live sustainably with our planet. Therefore, keeping track of the scientific status of the peer researches in geosciences could favour the researchers for learning about the latest research dynamics and policy makers from research organizations and governments for formulating relevant strategies.

In recent years, indicators based on highly cited papers (HCPs) have been widely used to evaluate the high-level scientific performance of researchers, research organizations, research fields and countries ${ }^{2-4}$. HCPs also play an important part in making higher education policies; for example, HCPs were both included as an evaluation index in the third (launched in 2012) and fourth (launched in 2016) round of China Discipline Ranking

Yanlin Cui is in the Library, China University of Petroleum (East China), Qingdao 266580, China.

*e-mail: cuiyl@upc.edu.cn led by the Ministry of Education of China ${ }^{5}$. Furthermore, global university rankings also take HCPs as a vital academic indicator ${ }^{6}$.

However, despite the extensive applications of HCPs in the above-mentioned areas, few attempts have been made to reveal the big picture about the high-level researches in the field of geosciences, based on HCPs. As such, the objective of this study is to analyse the basic properties of HCPs in the field of geosciences during the past 10 years. Characteristics like publication year, countries/regions, organizations, authors and journals are studied. Also, cutting-edge and compelling research topics within geosciences together with collaboration networks among countries/regions, organizations and authors are revealed.

\section{Data and method}

HCPs discussed in this study were collected from the database of the essential science indicators (ESI), which is based on a 10-year collection of data (publication and citation counts), updated bi-monthly (six times a year), covering 22 research fields of more than 11,000 journals. HCPs are defined in ESI as the top $1 \%$ of papers by citation frequency based on the most recent 10 years of publications. A total of $4295 \mathrm{HCPs}$ in the research field of 'geosciences' were exported on 25 July 2018, which cover a 10-year and 4-month period from 1 January 2008 to 30 April 2018. Among them, 4177 items were identified 


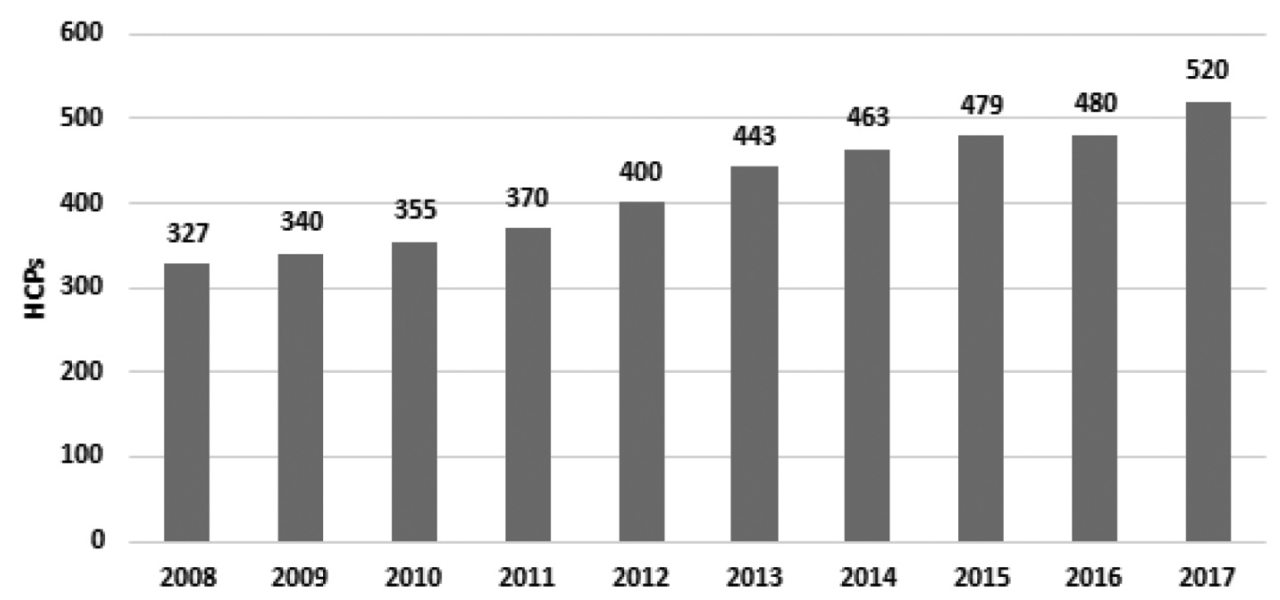

Figure 1. Annual variation of highly cited papers in geosciences.

for the period of 2008-2017 and re-searched in the platform of Web of Science (WoS) by 'accession number'. Then the results were saved directly in InCites, which is a citation-based evaluation tool for academic and government administrators to analyse institutional productivity and benchmark output against peers and aspirational peers in a national or international context ${ }^{7}$. The data saved in InCites were then employed for further analysis of publication trends, leading countries/regions, organizations, authors and top journals in geosciences. VOSviewer, an analytical tool introduced by van Eck and Waltman ${ }^{8,9}$, was also used in this study to determine collaboration networks among countries/regions, organizations or scholars.

\section{Results}

\section{Annual variation}

The 4177 HCPs identified in the research field of geosciences include 3492 articles $(83.6 \%), 672$ reviews $(16.1 \%)$ and 13 data papers $(0.3 \%)$. Figure 1 shows the variation of HCPs in geosciences during the period 20082017 with a steady increasing trend. The number of HCPs increased from 327 items in 2008 to 520 items in 2017, with a compound annual growth rate (CAGR) of 5\%. The years with increase in HCPs of over 30 items were 201112, 2012-13 and 2016-17.

\section{Countries/regions}

A total of 127 countries/regions contributed to the 4177 HCPs, and Figure 2 shows the top 10 productive ones. USA ranks first with a total number of 2534 HCPs accounting for $60.7 \%$ global share, followed distantly by England (922 HCPs, 22.1\%), China Mainland (864 HCPs, 20.7\%), Germany (786 HCPs, 18.8\%), France (620 HCPs, 14.8\%), Australia (519 HCPs, 12.4\%), Canada
(458 HCPs, 11.0\%), Switzerland (406 HCPs, 9.7\%), The Netherlands (356 HCPs, 8.5\%) and Japan (323 HCPs, $7.7 \%$ ).

In total, 1722 HCPs $(41.2 \%)$ were domestic (singlecountry) papers and $2455(58.8 \%)$ were papers by international collaboration. Worldwide, collaborations among researchers have been encouraged and considered to bring competitive advantages like cost-savings, more impactful researches and scientific progress ${ }^{10,11}$. The international collaboration ratio in geosciences seems higher than those in the other studied fields, like biomass $(24 \%)^{12}$, Information Science and Library Science $(27.2 \%)^{3}$, Antarctic $(31 \%)^{13}$, which indicates that there might be more high-impact papers in the research field of geosciences.

Figure 2 also gives the International collaborative HCPs of the top 10 countries/regions and their proportions. Apparently the lowest ratio of international collaborative HCPs appeared in USA (62.23\%), which can be considered as due to the fact that most of the top universities/institutions in geosciences are in that country (e.g. University of Colorado at Boulder, California Institute of Technology, Columbia University and Massachusetts Institute of Technology), which could lead to abundant high-level domestic collaborations. As the only developing country which appeared in the top 10, China Mainland has the second lowest international collaborations which is possibly related to the language barrier and uneven allocation of research resources ${ }^{14,15}$. It is interesting to note that European countries/regions, including England, Germany, France, Switzerland and The Netherlands tend to have more international collaborations represented here by higher percentage numbers (Figure 2 ), which could have been influenced by multiple factors, such as the short geographic distance among European countries $^{16,17}$ and European internal collaborations encouragement policy - the European Research Area (ERA) created by EU members which is dedicated to improving the internal coherence within the European research 


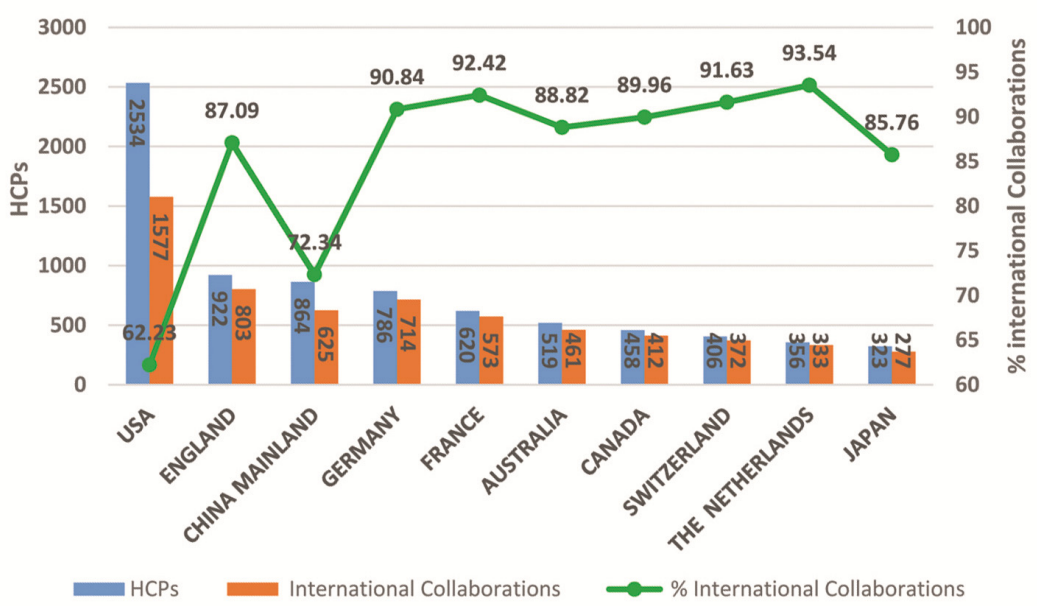

Figure 2. Top 10 countries/regions in geosciences by the number of HCPs.

landscape by coordination of regional, national and EU research activities ${ }^{18}$. Annual variations of the number of HCPs published by the top 10 countries/regions shown in Figure 3 could be used to measure their yearly performances of high-level scientific research in geosciences during the past 10 years. USA, the most productive country in the field, has shown steady increase in HCPs since 2008. On the other hand, HCPs of the other nine countries/regions, represented by England, China Mainland and Germany, have grown rapidly over the same period resulting in a substantial overall increase of world HCPs in geosciences. It is worth noting that the most significant increase happened in China Mainland, which contributed only 47 HCPs back in 2008, but the number tripled by 2017, making China Mainland rank second in the world. Another interesting point worth noting is that there is a boost in HCP numbers from 2012 to 2013. A similar, but small leap is also seen around 2012 in the total WoS documents (article and review only) in geosciences (which is also illustrated in Figure 3); here the increase that happened in China Mainland and USA is especially prominent. Further, the correlation coefficient (as a measure of the degree of linear association between two continuous variables) of the HCPs and the total WoS documents in geosciences is found to be as high as $0.96(P<0.01)$, suggesting that the overall prosperity in geosciences favours the production of high-level researches.

The most essential reason for the boost in both WoS papers and HCPs around 2012, seems to have been the increase in government funding. For example, in response to the Great Recession, USA developed the American Recovery and Reinvestment Act of 2009 (PL 111-5), and therefore in 2009 the US geosciences received the largest amount of funding till 2016 (ref. 19). On the other side of the world, China's funding for basic research has undergone rapid growth since the beginning of the 20th century. According to the Statistical Yearbook released by the National Bureau of Statistics of China, the coun- try's financial input in R\&D in basic sciences increased sharply from 4.67 billion Yuan (about 0.74 billion US dollars) in 2000 to 32.4 billion Yuan (about 5.1 billion US dollars) in 2010, and then surged to 82.3 billion Yuan (about 13.0 billion US dollars) in 2016 (ref. 20). Indeed there is a time lag between the funding year and the output year, because of the fact that it usually takes several years for scientists in geosciences to plan experiments, deploy instruments, get all the data needed, and finally have their results published ${ }^{21,22}$. Nevertheless, the considerable capital increase represented by USA and China has greatly stimulated the high-quality scientific research output in the top countries/regions.

Among the 127 countries/regions, 64 contributed at least $5 \mathrm{HCPs}$, and Figure 4 gives their collaboration networks. The size of the node corresponds to the amount of HCPs, and the distance between two nodes indicates the relatedness of the two countries in the collaborative network. It is apparent that the world HCPs in geosciences centre in USA, which is shown by the biggest node representing 1573 international collaborative HCPs. The most prominent collaborator for USA is England with 531 collaborative HCPs, accounting for $33.7 \%$; the other biggest collaborators include Germany (473 HCPs, $30.0 \%$ ), France (380 HCPs, 24.1\%), China Mainland (374 HCPs, 23.7\%), Canada (333 HCPs, 21.1\%) and Australia (281 HCPs, 17.8\%). From the global perspective, England, Germany and China Mainland are also the world's important nodes in the network of international collaborations, in addition to USA.

\section{Organizations}

We have identified 1772 organizations and the 15 most productive ones are shown in Table 1, including 12 from USA, 2 from China Mainland, and 1 from Switzerland. The large portion of USA organizations, 12 out of 15 , indicates the country's leading role in high-level 


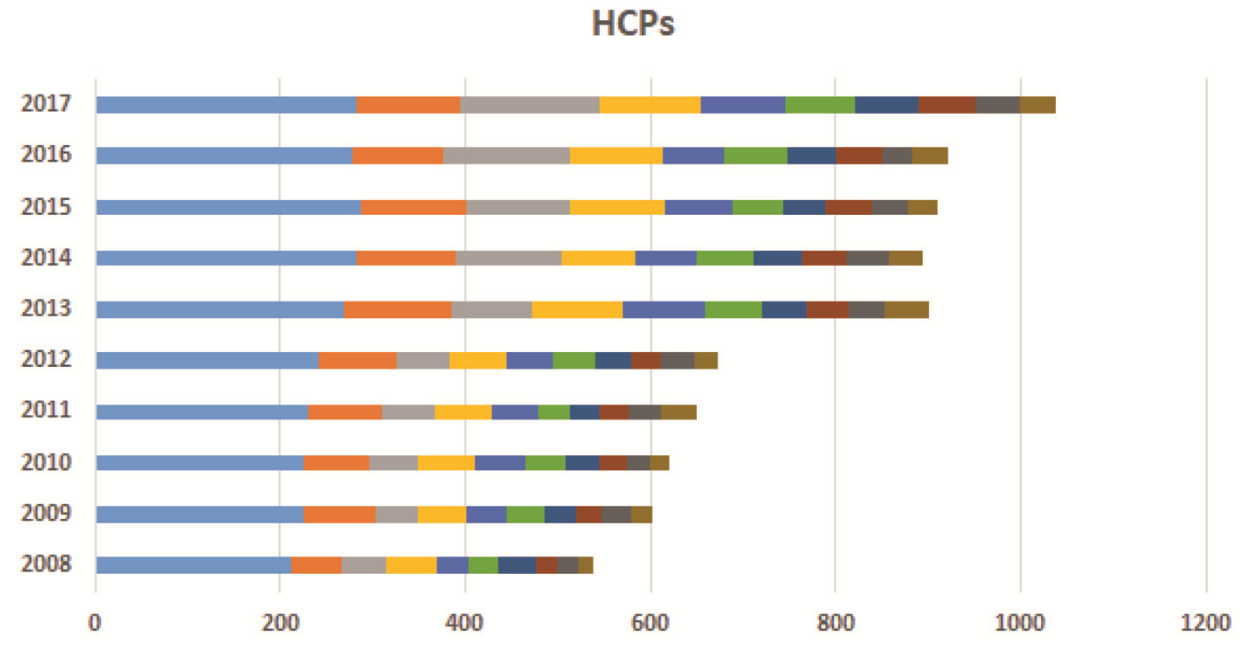

Web of Science documents

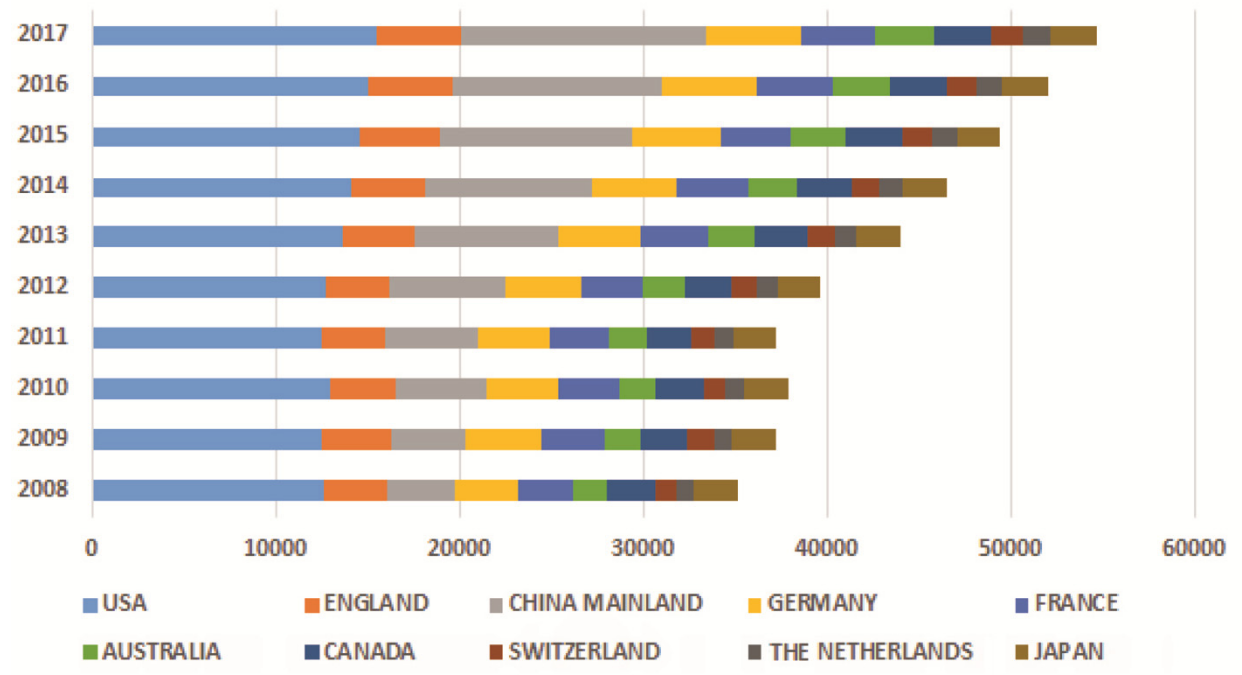

Figure 3. Annual variations of the number of HCPs (top) by the top 10 countries/regions and their corresponding Web of Science documents (bottom) in geosciences.

Table 1. Characteristics of the top 15 organizations in geosciences by total number of highly cited papers

\begin{tabular}{lcccl}
\hline Organization & HCPs & Citations & IC & Country/region \\
\hline National Oceanic and Atmospheric Administration (NOAA) & 384 & 77,498 & 64.3 & USA \\
Chinese Academy of Sciences (CAS) & 345 & 45,069 & 75.7 & China Mainland \\
National Aeronautics and Space Administration (NASA) & 334 & 58,133 & 70.7 & USA \\
University of Colorado & 274 & 46,252 & 67.2 & USA \\
National Center for Atmospheric Research (NCAR) & 269 & 62,450 & 67.7 & USA \\
California Institute of Technology (Caltech) & 257 & 24,951 & 66.5 & USA \\
ETH Zurich & 198 & 44,482 & 90.9 & Switzerland \\
University of Washington & 193 & 30,969 & 56.5 & USA \\
Columbia University & 178 & 29,027 & 64.0 & USA \\
University of Maryland & 176 & 30,631 & 73.9 & USA \\
United States Geological Survey (USGS) & 137 & 22,237 & 62.0 & USA \\
University of California, Berkeley & 133 & 22,466 & 73.7 & USA \\
University of California, San Diego & 129 & 22,556 & 64.3 & USA \\
China University of Geosciences & 121 & 17,640 & 78.5 & China Mainland \\
University of Princeton & 119 & 16,701 & 72.3 & USA \\
\hline
\end{tabular}

IC, \% International collaborations. 


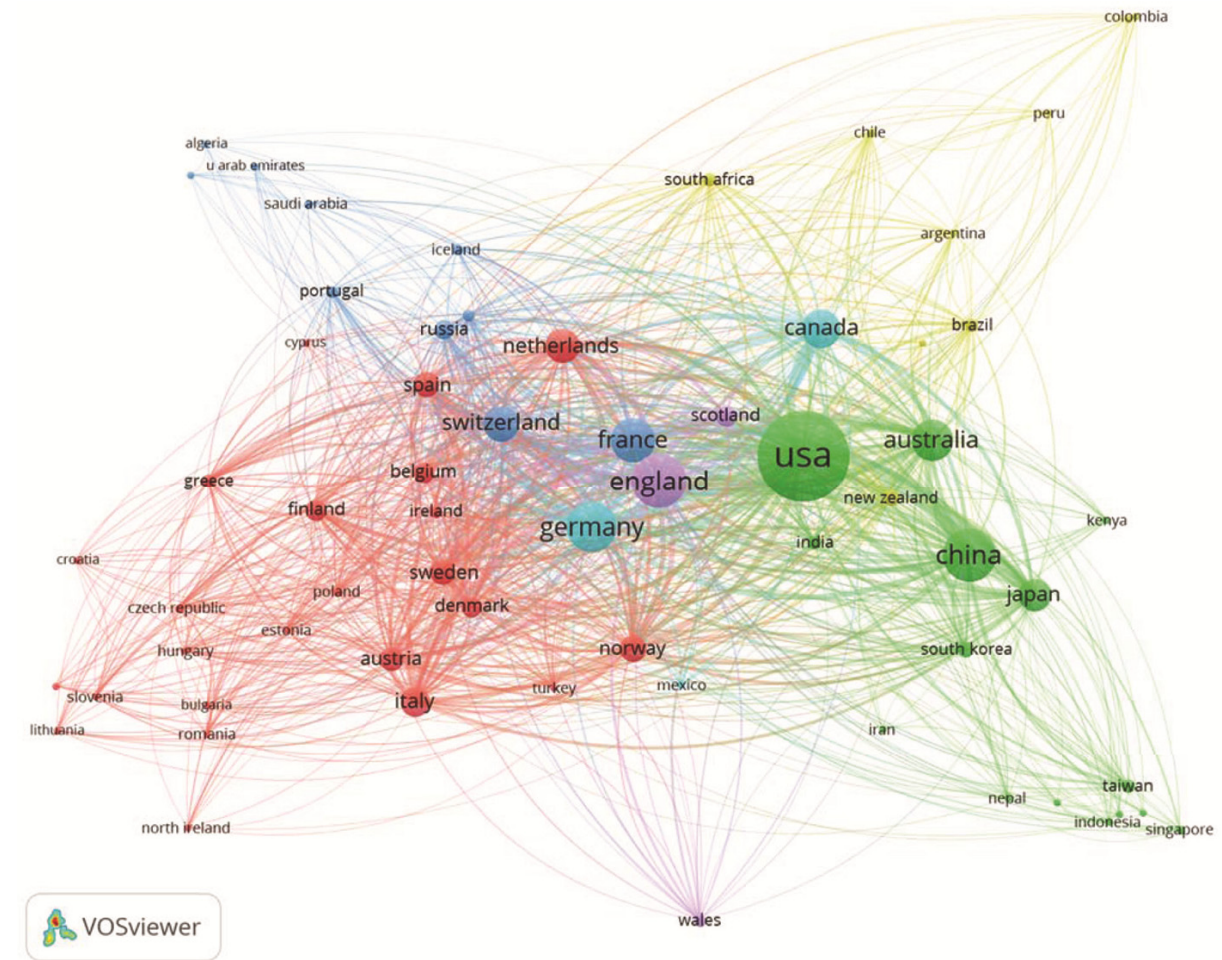

Figure 4. Collaboration network of 64 countries/regions with at least five HCPs.

scientific research in geosciences. There are only 3 organizations from the other top 10 countries/regions, suggesting that the geosciences' researches conducted worldwide are relatively concentrated in several top organizations. National Oceanic and Atmospheric Administration (NOAA), USA is the most productive organization which contributed 384 HCPs (9.2\%) with the highest citations. Chinese Academy of Sciences ranks the second with 345 HCPs $(8.3 \%)$, followed closely by National Aeronautics and Space Administration (NASA) with 334 HCPs $(8.0 \%)$.

Further analysis shows that there are 72 organizations owning at least $50 \mathrm{HCPs}$, and Figure 5 gives their collaboration network. The tangled web of relationships among those productive organizations apparently indicates that the influential organizations in geosciences could affect and connect mutually. Strong links exist among the top organizations, for example, NOAA, as the most productive organization revealed in Table 1 , has strong connections with NASA, CAS, NCAR, University of Colorado and the other productive organizations. However, as one of the top 15 organizations, China University of Geosciences seems to have less connections with other top productive organizations analysed in Figure 5, though its percentage of international collaboration is as high as 72.3. This indirectly shows that China University of Geosciences has conducted extensive collaborations worldwide with those less productive organizations owning HCPs no more than 50 .

\section{Authors}

The 4177 HCPs were authored by over 33,000 researchers, making the average number of authors per HCP 8.0, which is more than that in other documented fields, like economics and business $(2.1)^{4}$, Biomass (3.1) $)^{12}$, Antarctic $(5.0)^{13}$ and water resources $(3.5)^{23}$. This also reflects the extensive collaborations conducted in the research field of geosciences. Table 2 provides details of 15 of the most productive authors with at least 14 HCPs. Despite the dominance of USA in productivity, only 5 of the top 15 authors were from that country. On the other hand, Chinese researchers occupy six positions with four from China Mainland and two from Hong Kong, implying Chinese researchers are taking their place on the world stage. It is to be noted that Santosh M.'s HCPs were from two countries, because he worked at Kochi University Japan during 2000-2012 and has transferred to China University of Geosciences since 2012.

By the total number of HCPs, Ciais, P. of CEA (France) is the most productive author with $45 \mathrm{HCPs}$, followed closely by Jimenez, J. L. from the University of Colorado Boulder (USA) and Kulmala, M. from University of Helsinki (Finland), both with 41 HCPs. In terms of first-authored HCPs, among all the authors in Table 2, Santosh, M., Zhao, Guochun from University of Hong Kong, and Dai, Shifeng from China University of Mining and Technology all ranked first with 10 first-authored HCPs. Zhao, Guochun also ranks first by HCPs of 


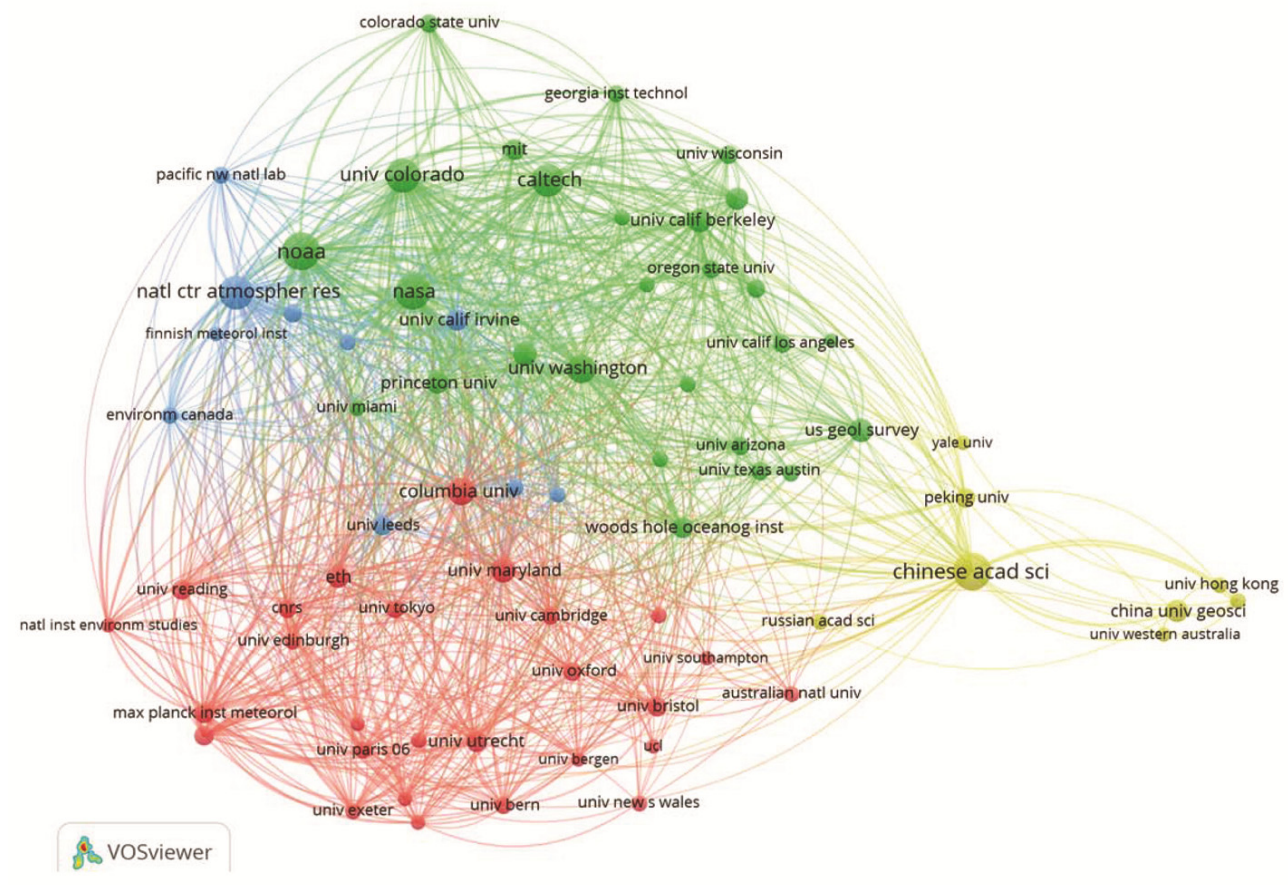

Figure 5. Collaboration network of 72 organizations with at least $50 \mathrm{HCPs}$.

Table 2. Fifteen of the most productive authors in geosciences by total number of HCPs

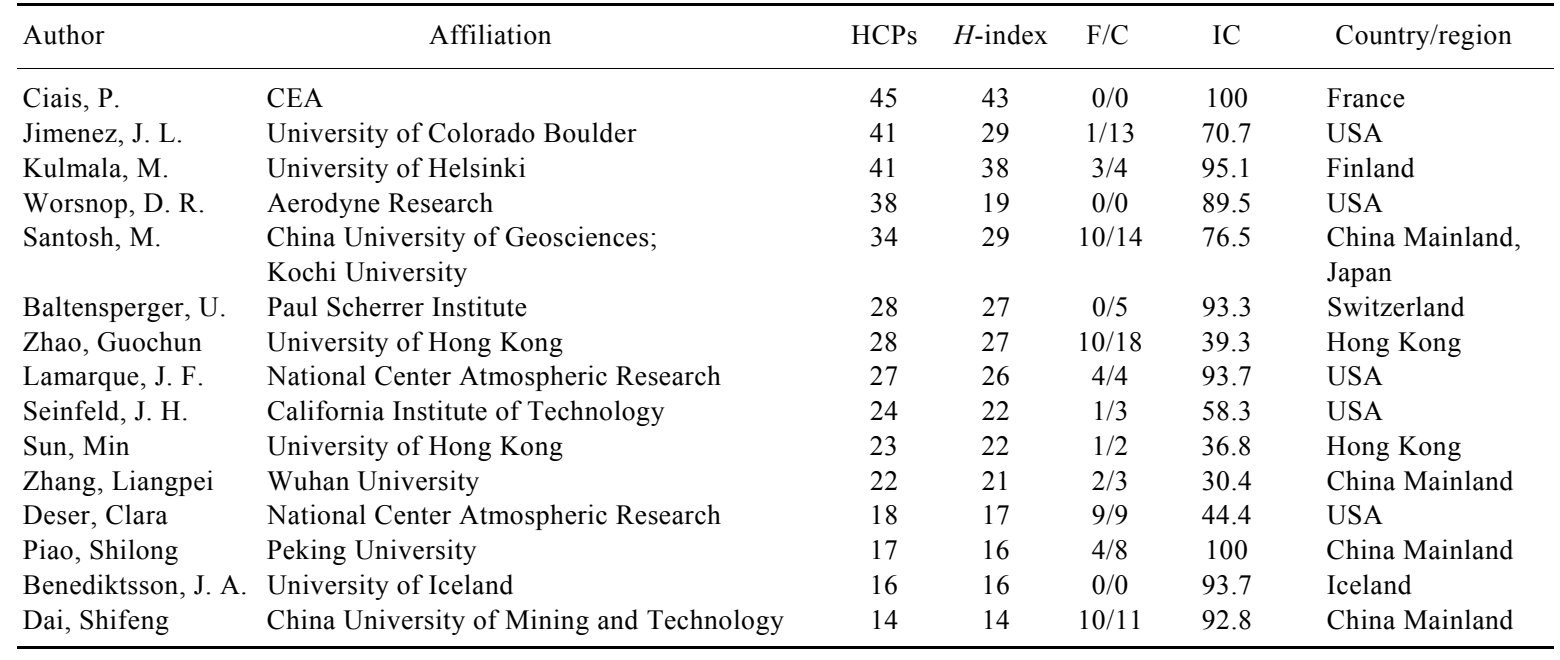

F/C, First author/corresponding author; IC, \% International collaborations.

corresponding author followed by Santosh, M. and Jimenez, J. L. Three of the top 15 authors, Ciais, P., Worsnop, D. R. and Benediktsson, J. A., had no first and corresponding authored HCPs; yet they are all very productive, indicating their contributions are mainly from international collaborations.

By analysing the variations in the number of HCPs published by these top 15 authors in any given year during 2008-2017 (Figure 6), their annual contribution to high-level research in geosciences could be revealed. It can be seen that, in the year of 2012, most of the top authors had fewer papers. Starting from 2013 till 2017, several authors, including Ciais, P., Jimenez, J. L., Kulmala, M., Worsnop, D. R. and Santosh, M. had their most productive research period. On the other hand, both Zhang, Liangpei and Dai, Shifeng's contributions to HCPs began from 2012 and gradually increased then on.

Following our examinations of author numbers and productivity, we found that there were 86 authors having at least 10 HCPs. Figure 7 further illustrates the author collaboration network. Among these 86 authors, 73 were inter-connected in some way, which could also be 


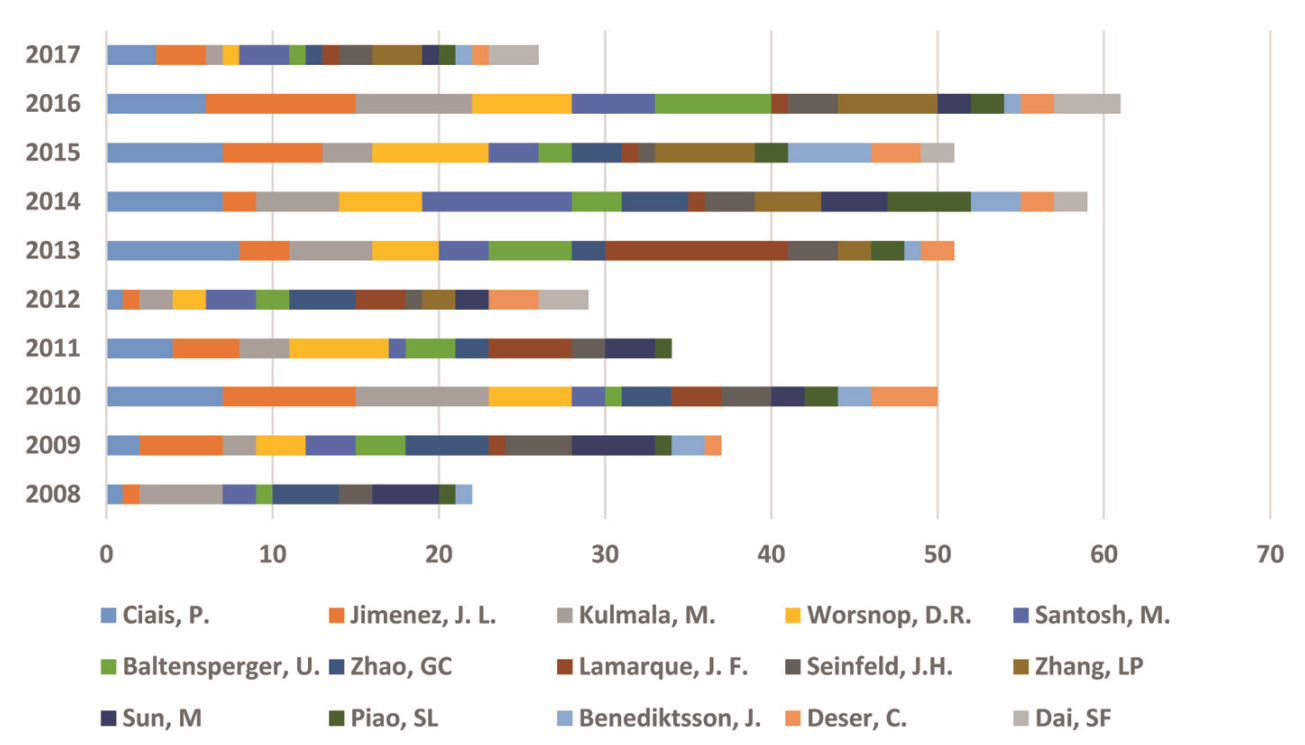

Figure 6. Fifteen of the most productive authors in geosciences by the number of HCPs published each year.

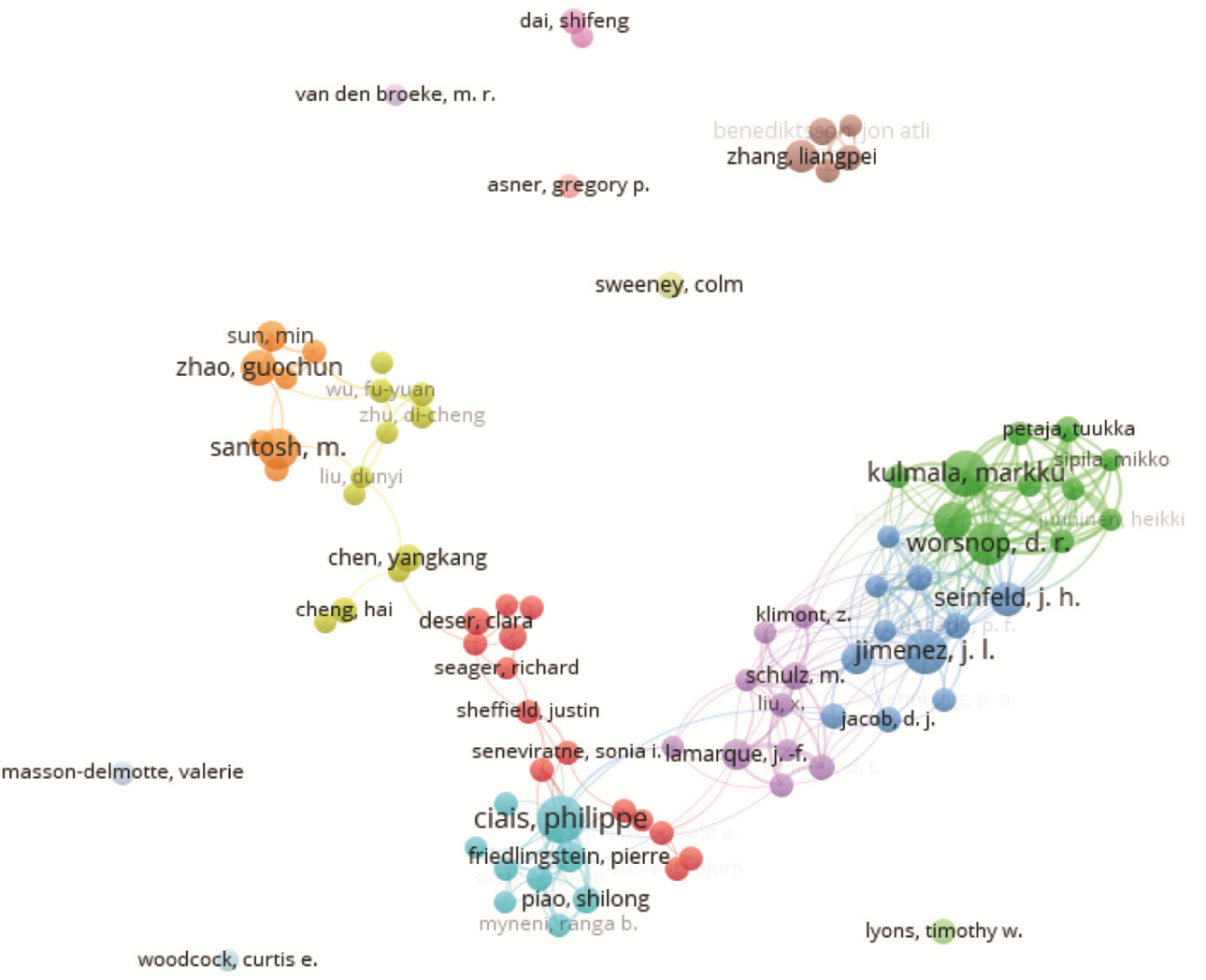

Figure 7. Collaboration network of 86 authors with at least 10 HCPs.

regarded as 73 of them can affect each other somehow in geosciences. From the size of the nodes which represents the total number of HCPs, the most productive authors are identified as Ciais, P., Jimenez, J. L., Kulmala, M., Worsnop, D. R., Santosh, M. and Zhao, Guochun, just as those presented in Table 2. As can be seen, the most productive authors in geosciences have been keeping close relationship with each other. Among them, Jimenez, J. L., Seinfeld, J. H., Kulmala, M. and Worsnop, D. R. have closer collaborations; Ciais, P. and Piao, Shilong are in the same cluster; Zhao, Guochun and Santosh, M. also have direct collaborations. Noting from Figure 5 that, only two of the top 20 authors, Dai, Shifeng and Zhang, Liangpei, have relatively isolated network, which might 
GENERAL ARTICLES

Table 3. Top 15 research categories in geosciences by total number of HCPs

\begin{tabular}{lrrr}
\hline Discipline & Rank & HCPs & Citations \\
\hline Geosciences, Multidisciplinary & 1 & 1458 & 240,743 \\
Meteorology and Atmospheric Sciences & 2 & 1330 & 270,638 \\
Geochemistry and Geophysics & 3 & 820 & 145,613 \\
Remote Sensing & 4 & 384 & 61,742 \\
Environmental Sciences & 5 & 346 & 67,351 \\
Imaging Science and Photographic Technology & 6 & 330 & 54,545 \\
Geography, Physical & 7 & 228 & 38,125 \\
Oceanography & 8 & 212 & 35,127 \\
Mineralogy & 9 & 137 & 18,384 \\
Engineering, Electrical and Electronic & 10 & 114 & 14,871 \\
Geology & 11 & 83 & 10,499 \\
Multidisciplinary Sciences & 12 & 78 & 21,414 \\
Marine and Freshwater Biology & 13 & 60 & 11,496 \\
Energy and Fuels & 14 & 56 & 6642 \\
Engineering, Geological & 15 & 50 & 7240 \\
\hline
\end{tabular}

explain why we can only trace their HCPs from 2012 because broader collaboration network usually brings high impact publications.

\section{Research areas and topics}

Publication rates and citation behaviour can vary considerably from one research area to another, and this is the reason why we usually discuss the performance of papers within the same research area. In this study, initially we collected all the HCPs discussed here from the research field of 'geosciences' based on the ESI scheme which is a broader scheme comprising 22 research areas. However, if we examine these HCPs using the WoS scheme, which is the narrowest categorization comprising 252 subject categories in science, social sciences, arts and humanities, we can find out the detailed subjects and emphasize those HCPs in geosciences.

Using Incites, the citation-based research analytics tool of Clarivate, a total of 36 research categories were identified by the WoS scheme, and Table 3 gives the top 15 categories by the total number of HCPs. The category of 'Geosciences, Multidisciplinary' ranks first with 1458 HCPs, followed closely by 'Meteorology and Atmospheric Sciences' with 1330 HCPs. 'Geochemistry and Geophysics' comes third with 820 HCPs. The list of the top 15 categories could be read as indicating that current high-end researches in geosciences focus on several subjects, including meteorology, geochemistry, geophysics, remote sensing, image science, oceanography and energy, etc.

Figure 8 shows the correlation network of research topics based on the co-occurrence of high frequency keywords (van Eck and Waltman, 2010; 2014). As can be seen, all research topics formed six clusters, which are labelled by different colours. The first cluster (red), also known as the biggest one represented by top number of
HCPs, is focused on researches about climate change, variability of ocean circulation, and sea surface temperature, which are carried out using numerical models. The second cluster (yellow) is also focused on climate change researches, but mainly based on studies from a chemical point of view, like emissions of carbon dioxide and methane. The third cluster (purple) is the study of the environment change based on particulate matter, aerosols, air pollution, etc. The key research topics of the fourth cluster (blue) concentrate on remote sensing and satellite product involving data precision, algorithm, validation, imagery, etc. The fifth cluster (cyan) focuses on studies on the polar regions covering topics like ice sheet, sealevel rise, glaciers, Antarctica/Arctic. Apparently the above five clusters all involve climate change researches, but with multidisciplinary perspectives. The sixth cluster (green), which is also the only relatively independent cluster, is about the researches related to tectonic evolution. Based on the presented correlation network of research topics, it is obvious that the researchers in geosciences are targeting climate change and try to study the climate change related phenomenon, mechanisms, consequences and solutions by different methods using observations and models.

\section{Journals}

In this study, 235 journals were confirmed to publish 4177 geosciences HCPs identified. Out of the 235 journals, $48(20.4 \%)$ published only one of those HCPs, and 21 journals $(8.9 \%)$ had two HCPs, while 73 journals (31.1\%) published more than 10 HCPs. Table 4 shows details of the top 15 productive journals having an average $\mathrm{IF}_{2017}$ of 11.0 that published a total of 2310 papers accounting for $55.3 \%$ of all HCPs. Among them, Nature was the most productive journal with 285 HCPs accounting for $6.8 \%$, followed closely by Science with 276 HCPs 


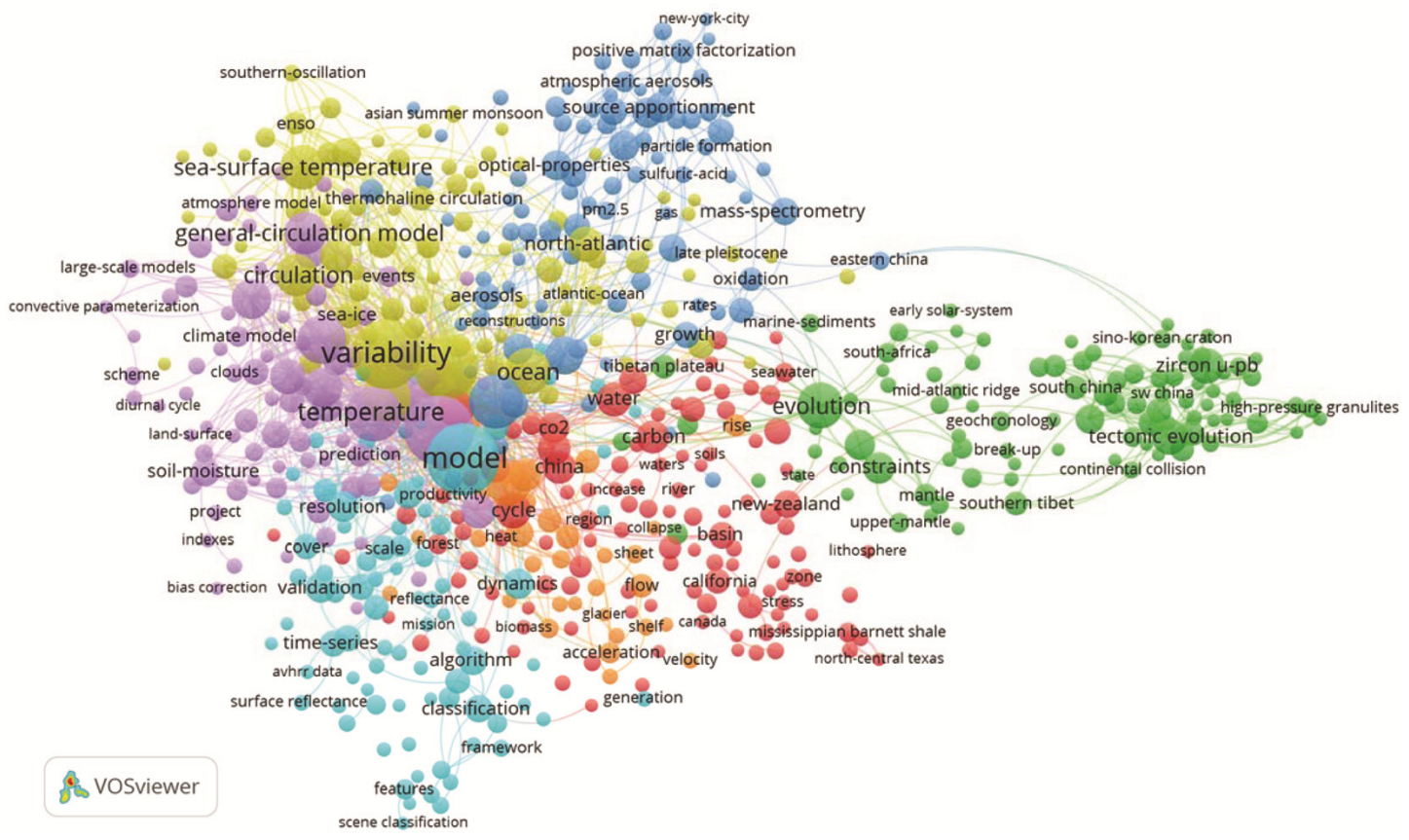

Figure 8. Correlation network of research topics based on the co-occurrence of high-frequency keywords.

Table 4. Top 15 journals by total number of HCPs

\begin{tabular}{|c|c|c|c|c|c|}
\hline Journal & HCPs $(\%)$ & $\mathrm{C} / \mathrm{P}$ & $\mathrm{IF}_{2017}$ & Web of Science category & Rank \\
\hline Nature & $285(6.8)$ & 211.4 & 41.577 & Multidisciplinary Sciences & $1 / 64$ \\
\hline Science & $276(6.6)$ & 256.0 & 41.058 & Multidisciplinary Sciences & $2 / 64$ \\
\hline Nature Geosciences & $242(5.8)$ & 156.8 & 14.391 & Geosciences, Multidisciplinary & $1 / 190$ \\
\hline Atmospheric Chemistry and Physics & $231(5.5)$ & 164.3 & 5.509 & Meteorology and Atmospheric Sciences & $4 / 86$ \\
\hline $\begin{array}{l}\text { Proceedings of the National Academy of } \\
\text { Sciences of the United States of America }\end{array}$ & $195(4.7)$ & 173.1 & 9.504 & Multidisciplinary Sciences & $5 / 64$ \\
\hline \multirow[t]{2}{*}{ Geophysical Research Letters } & $194(4.6)$ & 157.8 & 4.339 & Geosciences, Multidisciplinary & $11 / 190$ \\
\hline & & & & Environmental Sciences & $12 / 242$ \\
\hline \multirow[t]{2}{*}{ Remote Sensing of the Environment } & $165(4.0)$ & 180.5 & 6.457 & Imaging Science and Photographic Technology & $1 / 27$ \\
\hline & & & & Remote Sensing & $1 / 30$ \\
\hline \multirow[t]{2}{*}{ Journal of Climate } & $153(3.7)$ & 204.7 & 4.661 & Meteorology and Atmospheric Sciences & $7 / 86$ \\
\hline & & & & Engineering, Electrical and Electronic & $28 / 260$ \\
\hline \multirow{3}{*}{$\begin{array}{l}\text { IEEE Transactions on Geosciences and } \\
\text { Remote Sensing }\end{array}$} & $92(2.2)$ & 134.4 & 4.662 & Geochemistry and Geophysics & $6 / 85$ \\
\hline & & & & Imaging Science and Photographic Technology & $5 / 27$ \\
\hline & & & & Remote Sensing & $5 / 30$ \\
\hline Gondwana Research & $91(2.2)$ & 142.6 & 5.657 & Geosciences, Multidisciplinary & $6 / 190$ \\
\hline $\begin{array}{l}\text { Bulletin of the American Meteorological } \\
\text { Society }\end{array}$ & $90(2.2)$ & 235.5 & 7.804 & Meteorology and Atmospheric Sciences & $3 / 86$ \\
\hline $\begin{array}{l}\text { Journal of Geophysical Research } \\
\text { Atmospheres }\end{array}$ & $82(1.9)$ & 196.8 & 3.38 & Meteorology and Atmospheric Sciences & $18 / 86$ \\
\hline \multirow[t]{2}{*}{ Earth-Science Reviews } & $75(1.8)$ & 167.8 & 7.491 & Geosciences, Multidisciplinary & $4 / 190$ \\
\hline & & & & Environmental sciences & $55 / 242$ \\
\hline Atmospheric Environment & $72(1.7)$ & 205.1 & 3.708 & Meteorology and Atmospheric Science & $16 / 86$ \\
\hline Earth and Planetary Science Letters & $67(1.6)$ & 161.8 & 4.581 & Geochemistry and Geophysics & $8 / 85$ \\
\hline
\end{tabular}

$\mathrm{C} / \mathrm{P}$, Citations/paper; $\mathrm{IF}_{2017}$, Impact factor of 2017.

$(6.6 \%)$, both of which are the top journals in the category of 'Multidisciplinary Sciences' with the highest $\mathrm{IF}_{2017 \mathrm{~s}}$ of 41.577 and 41.058 respectively. The third most productive journal is Nature Geoscience with 242 HCPs (5.8\%) ranking first in the category of 'Geosciences, Multidisciplinary' with the third highest $\mathrm{IF}_{2017}$ of 14.391. It is interesting to note that, though Nature Geoscience was established only in January 2008, it has already established itself as a major journal for researchers in geosciences at a remarkable speed with the number of HCPs comparable to that of the other two top journals. Besides impact factor, the citations/paper $(\mathrm{C} / \mathrm{P})$ could 
GENERAL ARTICLES

Table 5. Top 15 funding agencies by total number of HCPs

\begin{tabular}{|c|c|c|c|c|}
\hline Funding agency & $\mathrm{HCPs}$ & Citations & $\mathrm{IC}$ & Country/region \\
\hline National Science Foundation & 963 & 172,823 & 60.44 & USA \\
\hline National Natural Science Foundation of China & 539 & 65,872 & 63.45 & China Mainland \\
\hline National Aeronautics and Space Administration (NASA) & 444 & 85,035 & 58.56 & USA \\
\hline United States Department of Energy (DOE) & 262 & 61,346 & 66.41 & USA \\
\hline National Oceanic Atmospheric Admin (NOAA) & 231 & 47,427 & 55.84 & USA \\
\hline National Basic Research Program of China & 204 & 27,770 & 69.12 & China Mainland \\
\hline NERC Natural Environment Research Council & 199 & 47,916 & 77.89 & UK \\
\hline European Union (EU) & 185 & 36,234 & 84.32 & EU \\
\hline German Research Foundation (DFG) & 122 & 19,425 & 79.51 & Germany \\
\hline Australian Research Council & 113 & 16,979 & 80.53 & Australia \\
\hline Chinese Academy of Sciences & 104 & 16,682 & 63.46 & China Mainland \\
\hline Natural Sciences and Engineering Research Council of Canada & 104 & 16,261 & 76.92 & Canada \\
\hline Swiss National Science Foundation & 98 & 19,880 & 80.61 & Switzerland \\
\hline European Research Council & 85 & 10,246 & 91.76 & EU \\
\hline French National Research Agency (ANR) & 77 & 8819 & 92.21 & France \\
\hline
\end{tabular}

IC, \% International collaborations.

also represent the research quality impact of a journal. The C/P indexes of those journals shown in Table 4 are all over 130 times with a maximum of 256.0 times for Science. The high $\mathrm{C} / \mathrm{P}$ together with high impact factor mentioned above indicate that the high-quality papers published in top influential journals tend to receive more attention and have more extensive impact/citations.

\section{Funding agencies}

Though funding is essential to academic research, here we only identified 2470 HCPs $(59.1 \%)$ that acknowledged grant support. The result is similar to that of a previous study which examined the funded paper ratios in the G9 countries with an average of $63.06 \%$ (ref. 24). Further, we identified a total of 257 funding agencies, and the Table 5 lists the top 15 by total number of HCPs.

Regarding the country/region distribution of the top 15 funding agencies, four of them are from USA, three from China Mainland, two from the EU, and one each from UK, Germany, Australia, Canada, Switzerland and France. Obviously, the top funding agencies in geosciences are mainly from USA and China Mainland, the two major research output producers. The US National Science Foundation (NSF) was listed as the number one funding agency which sponsored $963 \mathrm{HCPs}$, followed distant by the National Natural Science Foundation of China which funded 539 HCPs. NASA, DOE, and NOAA, as government agencies all from USA, ranked as third to fifth among funding organizations. National Basic Research Program of China ranked sixth, funding 204 HCPs. In terms of the international collaboration ratio of the funded HCPs, the results are consistent with those of an earlier study that funding agencies from EU countries have higher percentage numbers relative to other top countries/regions ${ }^{18}$.

\section{Conclusion}

As human population continues to grow, with everincreasing demands for water, food, environment and other resources, the pressure on the Earth is surely unprecedented. In this situation, geosciences serve as the interface between humans and the Earth, provides the knowledge that allows us to understand the current state of the Earth and make informed decisions and act responsibly while continuing to enjoy all the resources provided by our planet.

Based on 4177 HCPs in the research field of 'geosciences' retrieved from the ESI database from 2008 to 2017, this study provides an overview of the status of HCPs in the field of geosciences considering various aspects that include country/region productivity distribution, organizations, authors, research areas and hot topics and journals. It is revealed that over 33,000 researchers from 1772 organizations in 127 countries/regions contributed to the identified 4177 HCPs. The total HCPs in geosciences has shown a steady increase during the study period, which is consistent with the overall growth of WoS papers within the field. Considerable increase of government research funding has been suggested to have led to the growth of high-quality scientific research output. The top three productive regions are USA, England and China Mainland. Extensive collaborations prospered within the research fields. They are demonstrated by higher proportion of international collaborations and greater average number of authors than those in other documented fields. Besides, the European countries/ regions tend to have more international collaborations among themselves due to the short geographic distance between them and the European internal collaborations encouragement policy.

The University of California, USA is the most productive organization in terms of the total number of HCPs 
and citations, followed by France CNRS and NASA. Over 33,000 authors participated in publishing the 4177 HCPs, and the collaboration network shows that intensive collaborations exist among most productive authors. In spite of the dominance of USA in productivity, there are only 5 of the top 15 authors from that country, while Chinese researchers account for 6 . The current high impactmaking researches in geosciences are seen to be focusing on meteorology, geochemistry, geophysics, remote sensing and oceanography. Analysis of the correlation network of research topics based on the co-occurrence of high-frequency keywords shows that, currently the studies related to climate change, usually involving numerical models draw maximum attention.

Roughly $20 \%$ of HCPs containing significant research findings were published by the top journals like Nature, Science and Nature Geoscience, which undoubtedly could attract much more public attention and have profound influence. Conducting highly influential scientific work usually involves scientists from all over the world; for example, the HCP 'The next generation of scenarios for climate change research and assessment' published by Nature in 2010 with more than 3000 citations so far, was accomplished by 19 scientists affiliated to 13 organizations from 7 countries $^{25}$. This is a typical example of high-level research conducted by international collaborators in geosciences.

This study has revealed some basic characteristics of high-level researches in geosciences based on HCPs. However, it would have been more informative if we had comparable data regarding research funding of other countries besides USA and China. Future research should be conducted with more comprehensive data.

1. Earth Science; Wikipedia. https://en.wikipedia.org/wiki/Earth science. (accessed on 11 December 2018).

2. Pislyakov, V. and Shukshina, E., Measuring excellence in Russia: highly cited papers, leading institutions, patterns of national and international collaboration. J. Assoc. Infor. Sci. Technol., 2014, 65(11), 2321-2330.

3. Ivanović, D. and Ho, Y. S., Highly cited articles in the information science and library science category in social science citation index: a bibliometric analysis. J. Libr. Inf. Sci., 2016, 48, 36-46.

4. Zhang, N., Wan, S. and Wang, P., A bibliometric analysis of highly cited papers in the field of Economics and Business based on the Essential Science Indicators database. Scientometrics, 2018, 116, 1039-1053.

5. China Discipline Ranking (in Chinese). Baidu baike; https:// baike.baidu.com $/$ item $/ \% \mathrm{E} 5 \% \mathrm{AD} \% \mathrm{~A} 6 \% \mathrm{E} 7 \% \mathrm{~A} 7 \% 91 \% \mathrm{E} 8 \% \mathrm{AF} \% 84 \%$ E4\%BC\%B0/1651285? fr=aladdin (accessed on 4 December 2018).

6. The Best Global Universities rankings. US News; https:// www.usnews.com/education/best-global-universities/articles/methodology. (accessed on 10 December 2018).
7. Incites, https://clarivate.com/products/incites/. (accessed on 10 December 2018).

8. van Eck, N. J. and Waltman, L., Software survey: VOSviewer, a computer program for bibliometric mapping. Scientometrics, 2010, 84(2), 523-538.

9. van Eck, N. J. and Waltman, L., Visualizing bibliometric networks. Measuring Scholarly Impact, 2014, 285-320.

10. Borrett, S. R., Moody, J. and Edelmann, A., The rise of network ecology: maps of the topic diversity and scientific collaboration. Ecol. Model, 2014, 293, 111-127.

11. Wang, Q. and Li, R. R., Research status of shale gas: a review. Renew. Sustain. Energ. Rev, 2017, 74, 715-720.

12. Chen, H. and Ho, Y. S., Highly cited articles in biomass research: a bibliometric analysis. Renew. Sustain. Energ. Rev., 2015, 49, $12-20$.

13. Fu, H. Z. and Ho, Y. S., Highly cited Antarctic articles using Science Citation Index Expanded: a bibliometric analysis. Scientometrics, 2016, 109, 337-357.

14. Amano, T., González-Varo, J. P. and Sutherland, W. J., Languages are still a major barrier to global science. PLoS Biol., 2016, 14(12), e2000933.

15. Johnson, N. G., Decision making limitations from communication barriers in government structures in Chinese rural energy projects. Master Thesis, Iowa State University, USA, 2008.

16. Hoekman, J., Frenken, K. and Tijssen, R. J. W., Research collaboration at a distance: changing spatial patterns of scientific collaboration within Europe. Res. Policy, 2010, 39, 662-673.

17. Daraio, C. and Moed, H. F., Is Italian science declining? Res. Pol., 2011, 40, 1380-1392.

18. Commission of the European Communities, Green paper. The European Research Area: New Perspectives. \{SEC(2007) 412\}, $\operatorname{COM}(2007) 161$ final, Brussels, 4 April 2007.

19. NSF budget requests to Congress and annual appropriations, National Science Foundation (US); https://www.nsf.gov/about/ budget/index.jsp. (accessed on 3 January 2019).

20. China Statistical Yearbook, National Bureau of Statistics of China. http://www.stats.gov.cn/tjsj/tjcbw/201810/t20181024_1629505. html (accessed on 20 December 2018).

21. Allen, R., Forsyth, D., Gaherty, J., Orcutt, J., Toomey, D. and Trehu, A., Ocean bottom seismology workshop report. IRIS Consortium, 2012, p. 40.

22. NASA's Earth Science mission portfolio, Report No. IG-17-003; https://oig.nasa.gov/docs/IG-17-003.pdf. (accessed on 28 December 2018).

23. Chuang, K. Y., Wang, M. H. and Ho, Y. S., High-impact papers presented in the subject category of water resources in the essential science indicators database of the institute for scientific information. Scientometrics, 2011, 87, 551-562.

24. Huang, M. H. and Huang, M. J., An analysis of global research funding from subject field and funding agencies perspective in the G9 countries. Scientometrics, 2018, 115, 833-847.

25. Moss, R. H. et al., The next generation of scenarios for climate change research and assessment. Nature, 2010, 463, 747-756.

Received 8 March 2019; revised accepted 13 August 2019

doi: $10.18520 / \mathrm{cs} / \mathrm{v} 118 / \mathrm{i} 4 / 532-542$ 